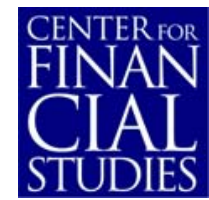

No. $2007 / 16$

Gradualism, Transparency and Improved Operational Framework:

A Look at the Overnight Volatility Transmission

Silvio Colarossi and Andrea Zaghini 


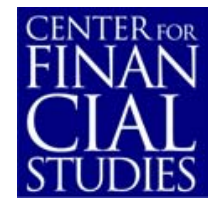

\section{Center for Financial Studies}

The Center for Financial Studies is a nonprofit research organization, supported by an association of more than 120 banks, insurance companies, industrial corporations and public institutions. Established in 1968 and closely affiliated with the University of Frankfurt, it provides a strong link between the financial community and academia.

The CFS Working Paper Series presents the result of scientific research on selected topics in the field of money, banking and finance. The authors were either participants in the Center's Research Fellow Program or members of one of the Center's Research Projects.

If you would like to know more about the Center for Financial Studies, please let us know of your interest.

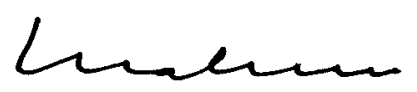

Prof. Dr. Jan Pieter Krahnen

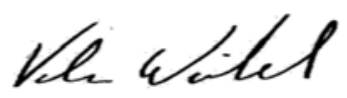

Prof. Volker Wieland, Ph.D. 
CFS Working Paper No. 2007/16

\title{
Gradualism, Transparency and \\ Improved Operational Framework: \\ A Look at the Overnight Volatility Transmission
}

\author{
Silvio Colarossi ${ }^{1}$ and Andrea Zaghini ${ }^{2}$
}

March 2007

\begin{abstract}
:
This paper proposes a possible way of assessing the effect of interest rate dynamics on changes in the decision-making approach, communication strategy and operational framework of a Central bank. Through a GARCH specification we show that the USA and Euro area displayed a limited but significant spillover of volatility from money market to longer-term rates. We then checked the stability of this phenomenon in the most recent period of improved policymaking and found empirical evidence that the transmission of overnight volatility along the yield curve vanished soon after specific policy changes of the FED and ECB.
\end{abstract}

JEL Classification: E4, E5, G1

Keywords: Monetary Policy, Yield Curve, GARCH. 


\section{Introduction ${ }^{1}$}

The understanding of Central banks' actions by the public is as important as the actions themselves. Indeed, the comprehension of the monetary policy decision-making process and the way expectations about future moves are formed directly influence the effectiveness of monetary policy itself. Eventually, the success of current changes in official rates in affecting spending decisions by households and investment by firms is almost entirely dependent on the impact of such changes on other financial markets' prices and yields, such as longer-term interest rates, equity prices and exchanges rates, which in turn depend on the expectations of future developments in official rates.

Many Central banks have attempted in recent years to reduce the uncertainty arising from policy decisions. To this end, important changes in the conduct of monetary policy have been implemented. New trends have emerged since the early 1990s: (i) an increase in the amount of information regularly released to the public aimed at explaining in details the decisions of the policy maker; (ii) a move towards gradualism in policy action, namely the tendency to adjust policy rates in small steps in the same direction; (iii) improvements in monetary policy operational frameworks and clearer implementation rules.

In order to influence private sector expectations, and driven by the idea that a broad knowledge of the decision-making process by the public would make the monetary policy authority's job easier, Central banks make an effort to provide in an open, clear and timely manner all the relevant information about the underlying strategy, the final and intermediate targets and the related horizon (Woodford, 2005). A second way in which the monetary authorities try to influence expectation formation is by establishing certain patterns of behaviour (Bernanke, 2004). In fact, under a gradualist regime the Central bank leads market participants to anticipate that changes in the policy rate will be followed by further changes in the same direction. In addition, they will almost certainly be able to anticipate the magnitude of the changes: variations in excess of 25 basis points have been increasingly rare

\footnotetext{
${ }^{1}$ We would like to thank Paolo Angelini, Michele Manna, Benjamin Sahel and participants to the XV Tor Vergata Conference on Banking and Finance, to the II ICEEE Congress and to seminars held at the European Central Bank and the Goethe University of Frankfurt for very helpful suggestions and discussions. The paper does not necessarily reflect the views of the Banca d'Italia.
} 
in industrial economies. For instance, between January 2001 and June 2003 the FED reduced its policy rate 13 consecutive times, while from June 2004 it increased it 17 times (all of them by 25 basis points). At the same times the ECB maintained a similar approach: the last change of 50 basis points was June $2003 .^{2}$

Finally, operational frameworks have undergone important changes to avoid an additional source of noise in the communication and implementation of monetary policy stance. Since the implementation of monetary policy decisions typically takes place through the steering of very short-term interest rates, high volatility in money market rates may potentially obscure the signalling of the policy stance. In particular, Central banks are concerned about the possible weakening of the "neutrality" of liquidity management. A liquidity policy is "neutral" whenever the monetary policy stance is determined by the decisions taken by the competent policy-making body with respect to official rates, rather than influenced by the management of liquidity conditions. ${ }^{3}$

There is broad agreement that enhanced operational procedures together with better communication strategies and increased transparency have improved the predictability of Central banks decisions, reduced the volatility in the money market and enhanced the signalling content of very short-term rates (Hilton; 2005, Woodford; 2005, Issing; 2005). Less firm evidence is available concerning the consequences of the increased monetary policy predictability: has it had any appreciable consequence on some variables of interest? Here the evidence is less clear-cut. Attempts at testing the hypothesis that better monetary policymaking may be the cause of improved macroeconomic performance over the last 20 years have been made. For instance, Stock and Watson (2002) argue that better policymaking is unlikely to be a main cause of the great moderation (reduced GDP and inflation variability) since 1985 . However, the quest for such effects may pose serious

\footnotetext{
${ }^{2}$ Another argument in favour of gradualism concerns the uncertainty in which Central bankers operate. A primary source of uncertainty relates to the partial knowledge of the underlying structure of the economy (Brainard, 1967). An additional source is related to the fact that economic data is dynamic and significant updates are quite frequent, so that policymakers are called to make decisions with imperfect knowledge of the current state of the economy (Orphanides, 2003). For other arguments in favour and against gradualism in monetary policy see among others Rudebush (2001), Söderström (2002), Woodford (2003), Angeloni et al. (2003).

${ }^{3}$ See Furfine (2003), Clews (2005) and Durré and Nardelli (2007).
} 
identification problems. Obvious intermediate steps in this search may focus on the effect of specific policy changes on variables directly related to monetary policy decisions. Demiralp and Jordà (2004) examine the reaction of the term structure to the explicit announcement of the Federal funds rate target, initiated by the FED in 1994. They found that after 1994 the reaction of longer term rates to surprises in the target tends to decline relative to the pre-1994 period, and argue that this reduced response may indeed have been driven by better understanding of the way policy works. In addition, Swanson (2006) shows that financial markets and private sector forecasters have become better able to forecast the FED funds rate at horizon out to several months and that the increase in FED transparency played an important role since similar improvements in private sector forecasts of GDP and inflation did not occur.

In this paper we attempt an alternative route to gauge the effects of improved monetary policymaking on interest rates: we analyse the transmission of volatility along the yield curve and more specifically, we first assess the extent to which volatility is transmitted from policy instrument rates to longer maturities. In line with previous literature, we find that some volatility spillover is indeed present, both in the US and the Euro area, over an extended time span. Next, we check whether this volatility transmission is stable over time or whether structural changes can be detected in concomitance with episodes of policy reform. In principle, the spillover of volatility from the overnight rate to longer maturities may be viewed as a market flaw. Higher volatility may translate into term premia, thereby increasing equilibrium levels of nominal and real long-term rates and disturbing the transmission mechanism of monetary policy impulses. In this regard, the policy trends mentioned above should have had a dampening effect on volatility transmission, improving monetary policy effectiveness. A change (reduction) in the volatility transmission is used here as an indicator of the enhanced effectiveness of the monetary policy and thus for the benefit of the implemented changes. We found that volatility transmission had not only declined in recent years, but completely vanished.

Tests of structural break with unknown breakpoint suggest that the drop in volatility transmission has occurred close to specific policy changes, both in the US and the Euro area. Specifically, in the former the break is recorded soon after the introduction in the statements of post-FOMC meetings of an explicit "balance of risk" to the economic outlook, while in 
the latter immediately after the launch of a new operational framework. Overall, our findings are consistent with the idea that improvements in the monetary policy framework may be responsible for the documented changes in the behaviour of volatility transmission.

This paper is structured as follows: Section 2 provides the model specifications for the overnight rate and the volatility transmission along the yield curve; Section 3 assesses the evolution of the pass-through mechanism in the most recent period of improved policymaking; Section 4 concludes.

\section{Volatility transmission along the yield curve}

\subsection{The overnight market}

Our empirical strategy is the following. In this Subsection and the next we try to identify satisfactory statistical models for interest rates at various maturities and to test for the presence of volatility transmission from the shortest end of the yield curve (the overnight market) to longer maturities. In Section 3 we then assess whether the recent changes in the monetary policy operational procedures and in the way communication with the public is managed may have had an impact on these models (e.g. generated some structural instability).

A first lesson that can be drawn from the empirical literature is that several methods are used to measure volatility, each with advantages and shortcomings. However, in recent years the conditional-volatility modelling (ARCH and its variants) has quickly gained relevance and is nowadays one of the most used tools in applied financial research. ${ }^{4}$ Thus, along the line of empirical studies on the same topic and given the relatively similar

\footnotetext{
${ }^{4}$ See Engle (1983) and Bollerslev (1986) for the seminal contributions. A second important strand of empirical financial research is instead based on the concept of realized volatility (Andersen and Bollerslev, 1997; 1998). As for the most recent empirical contributions see Bomfim (2003), Demiralp et al. (2006), Bali and Wu (2006) for the USA, while for the Euro area refer to Hartman et al. (2001), Perez-Quiros and Rodriguez (2006), Nautz and Offermanns (2007). Prati et al. (2003) and Bartolini and Prati (2006) provide cross-country studies of the different behaviour of overnight markets in several industrialised economies including USA and Euro area.
} 
operational framework of the FED and ECB, we adopt the following GARCH model for the USA and the Euro area overnight interest rates: ${ }^{5}$

$$
\begin{aligned}
& \Delta r_{t}=\theta+\rho(r-o)_{t-1}+\sum_{j} \varphi_{j} \Delta r_{t-j}+\sum_{j} \eta_{j} \Delta o_{t-j}+\tau \sigma_{t}^{2}+\omega D X_{t}+\varepsilon_{t} \\
& \sigma^{2}{ }_{t}=v+\alpha \varepsilon^{2}{ }_{t-1}+\beta \sigma_{t-1}^{2}+\gamma \varepsilon_{t-1}^{2} S_{t-1}^{-}+\psi D X_{t} .
\end{aligned}
$$

In the mean equation (1) $r_{t}$ denotes the nominal overnight interest rate, $o_{t}$ is the official interest rate, $D X_{t}$ is a matrix of calendar dummies. In the variance equation (2) the dummy variable $S_{t}$, which takes the value 1 if $\varepsilon_{\mathrm{t}}<0$ and 0 otherwise, allows for a different reaction of volatility to positive and negative surprises (Glosten et al., 1993). We modelled the overnight rate in differences, since each rate turned out to be an I(1) variable, and introduced as Error Correction Term the spread between the overnight and the official rate. We also added several dummy variables to take into account calendar effects (end of month, quarter and year) and maintenance period effects both in the mean and variance equation. The conditional variance process together with the conditional mean specification was jointly estimated using the maximum likelihood technique. ${ }^{6}$

Regarding the US overnight market, we use the Federal Funds effective rate (FF) as the endogenous variable and the Funds target as the official rate. The latter rate has been publicly announced since February 1994, while in the preceding years, the FOMC did not formally target the Funds rate. Accordingly, our sample period starts in March 1994 and ends in February 2006. In the mean equation, the impact effect of a 1 percentage point change in the target rate on the overnight rate is 0.54 points (Table 1 ). Thereafter, almost any remaining differential between official and overnight interest rate is removed at the very high rate of 79 per cent per period (the ECT coefficient). On the final business day of each month - the so-called high-payment-flow days - we detect an increase of both conditional mean and volatility. With reference to the other calendar day effects, we find that the parameter on the end-quarter dummy is strongly positive while that at the year end is significantly negative. In addition, evidence of a positive effect is found on the last days of

\footnotetext{
${ }^{5}$ See Board of Governors of the Federal Reserve System (2005) and European Central Bank (2005) for a detailed description of the operational framework of the two Central banks.

${ }^{6}$ See Table A1 and A2 in the Appendix for the exact data definition and dummy specification.
} 
the maintenance period. A dummy variable valued 1 in the days after the terrorist attack on 11 September 2001 takes into account the extraordinary changes in the FF rate in those days, while, the coefficient $\gamma$ turn out to be significant, suggesting evidence of asymmetric effects in volatility. ${ }^{7}$

Table 1

\section{ESTIMATION RESULTS FOR OVERNIGHT MARKETS}

\begin{tabular}{|c|c|c|c|c|c|}
\hline \multicolumn{6}{|c|}{ Fed Funds } \\
\hline$\theta$ & -0.0048 & $* *$ & $v$ & 0.0018 & $* *$ \\
\hline$\rho$ & -0.7884 & $* *$ & $\alpha$ & 0.3642 & $* *$ \\
\hline$\varphi_{1}$ & 0.0898 & $* *$ & $\beta$ & 0.1181 & $* *$ \\
\hline$\varphi_{2}$ & 0.0855 & $* *$ & $\gamma$ & 0.1990 & $* *$ \\
\hline$\varphi_{3}$ & 0.1084 & $* *$ & $\psi_{\mathrm{EM}}$ & 0.0078 & $* *$ \\
\hline$\eta_{0}$ & 0.5357 & $* *$ & $\psi_{\mathrm{EQ}}$ & 0.1779 & $* *$ \\
\hline$\omega_{\mathrm{EM}}$ & 0.0954 & $* *$ & $\psi_{\text {EEEMP }}$ & 0.0012 & $* *$ \\
\hline$\omega_{\mathrm{BM}}$ & 0.0477 & $* *$ & $\psi_{\text {EEMP }}$ & 0.0039 & $* *$ \\
\hline$\omega_{\mathrm{EQ}}$ & 0.2240 & $* *$ & $\psi_{\mathrm{EMP}}$ & 0.0133 & $* *$ \\
\hline$\omega_{\mathrm{EY}}$ & -0.5673 & $* *$ & & & \\
\hline$\omega_{\text {EEEMP }}$ & 0.0312 & $* *$ & & & \\
\hline$\omega_{\text {EMP }}$ & 0.0178 & $*$ & & & \\
\hline$\omega_{9 / 11 / 2001}$ & -0.7125 & $* *$ & & & \\
\hline \multicolumn{6}{|c|}{ EONIA } \\
\hline$\theta$ & 0.0108 & $* *$ & $v$ & 0.0002 & ** \\
\hline$\rho$ & -0.2390 & $* *$ & $\alpha$ & 0.2466 & $* *$ \\
\hline$\varphi_{1}$ & -0.0594 & * & $\beta$ & 0.3541 & $* *$ \\
\hline$\eta_{0}$ & 0.3924 & $* *$ & $\psi_{\mathrm{EM}}$ & 0.0022 & $* *$ \\
\hline$\omega_{\mathrm{EM}}$ & 0.0338 & $* *$ & $\psi_{\mathrm{BM}}$ & -0.0032 & $* *$ \\
\hline$\omega_{\mathrm{EQ}}$ & 0.0525 & $* *$ & $\psi_{\text {EЕEMP }}$ & 0.0062 & $* *$ \\
\hline \multirow[t]{2}{*}{$\omega_{\mathrm{EMP}}$} & -0.0010 & $*$ & $\psi_{\text {EEMP }}$ & 0.0405 & $* *$ \\
\hline & & & $\psi_{\mathrm{EMP}}$ & 0.0079 & $*$ \\
\hline
\end{tabular}

NOTE: Daily observations. Sample period: 1.3.1994 - 28.2.2006 for the USA and 1.1.1999 - 28.2.2006 for the Euro Area. An (two) asterisk(s) denotes statistical significance at $95 \%$ (99\%).

Regarding the Euro area overnight market we rely on the EONIA rate (Euro OverNight Index Average), while we consider the rate on the MROs (Main Refinancing Operations) as

\footnotetext{
${ }^{7}$ The diagnostic statistic LM2 did not detect any residual heteroskedasticity up to fifth order. The stability condition of the GARCH model is always satisfied $(\alpha+\beta<1)$ and the non negativity of the conditional variance is ensured by the positive value of $v, \alpha$ and $\beta$.
} 
the official rate. Our sample period ranges from January 1999 to February 2006. The meanvariance model appears reasonably well-specified: the diagnostic test for ARCH effects (LM2) up to fifth order is easily satisfied and most parameters values turned out to be as expected. In the mean model, the impact effect of a change of 1 percentage point in the official interest rate is 0.39 points in the overnight rate (Table 1). Thereafter, any remaining differential between official and overnight interest rate is eradicated at the rate of 24 per cent per period. Most likely due to window-dressing effects, on the last day of the month and of the quarter the EONIA rate increases by 3 and 5 basis points, respectively. As for the variance equation, an increase in volatility is detected in the last days of the maintenance period and at the end of the month (Moschitz; 2004, Prati et al.; 2006, Peres-Quiros and Rodriguez; 2006).

\subsection{Volatility transmission}

The volatility in the overnight market is usually interpreted as a "technical" volatility mainly due to banks' liquidity management, i.e. it is not directly related to the monetary policy stance of the Central bank. However, the communication policy of the Central bank and possible changes in the monetary policy strategy may indirectly affect the overnight market. In fact, there is the risk that the volatility in the daily money market is unwarrantly transmitted to longer-term rates, which are relevant to real economic decisions such as firms' investment and households' consumption. This is why, among other reasons, monetary authorities try to stabilise volatility in the very short-end of the yield curve and to be as transparent as possible in the management of its decision-making process.

In order to assess the existence of the volatility transmission across maturities, we introduce the conditional variance derived from the overnight GARCH model as an exogenous variable in the estimates of the volatility model at longer maturities. This procedure implicitly assumes that overnight volatility is not Granger-caused by longer-term interest rate innovations and thus that the transmission may go in one direction only (Ayuso et al.; 1997). In addition, the conditional variance is introduced as an explanatory variable also in the mean equation of each maturity date to check for a possible direct effect of the volatility on the level of interest rates. Then, equations (1) and (2) become: 
(3)

$$
\Delta r_{t}^{i}=\theta^{i}+\rho^{i}\left(r^{i}-o\right)_{t-1}+\sum_{j} \varphi_{j}^{i} \Delta r_{t-j}^{i}+\sum_{j} \eta_{j}^{i} \Delta o_{t-j}+\tau^{i} \sigma_{t}^{2, i}+\omega^{i} D X_{t}+k^{i} \sigma_{t}^{2, o n}+\varepsilon_{t}^{i}
$$

(4)

$$
\sigma^{2, i}{ }_{t}=v^{i}+\alpha^{i} \varepsilon^{2, i}{ }_{t-1}+\beta^{i} \sigma_{t-1}^{2, i}+\lambda^{i} \sigma_{t}^{2, o n}+\psi^{i} D X_{t}
$$

where $r^{i}$ denotes the nominal interest rate with maturity $i=1$-month, 3-month, 12-month, 5year and 10-year and the suffix on stands for the overnight market.

Table 2

\begin{tabular}{|c|c|c|c|c|c|c|c|c|c|c|}
\hline & 1-month & & 3-month & & 12-month & & 5 -year & & 10-year & \\
\hline $\bar{\theta}$ & 0.0017 & & 0.0016 & & 0.0009 & & 0.0005 & & -0.0008 & \\
\hline$\rho$ & -0.0155 & $* *$ & & & & & & & & \\
\hline$\varphi_{1}$ & 0.1262 & $* *$ & 0.1134 & * & 0.0338 & * & 0.0577 & $* *$ & 0.0542 & $* *$ \\
\hline$\varphi_{2}$ & & & & & 0.0354 & $*$ & & & & \\
\hline$\eta_{0}$ & 0.0513 & $* *$ & -0.0405 & $* *$ & 0.0446 & $* *$ & & & & \\
\hline$\omega_{\mathrm{EM}}$ & & & & & & & -0.0226 & $* *$ & -0.0209 & $* *$ \\
\hline$\omega_{\mathrm{EY}}$ & & & & & & & -0.0281 & $*$ & 0.0242 & $*$ \\
\hline$\omega_{9 / 11 / 2001}$ & 0.1941 & $* *$ & -0.1238 & $* *$ & & & & & & \\
\hline$k$ & 0.0080 & & 0.1230 & & 0.0230 & & -0.0043 & & 0.0019 & \\
\hline$v$ & 0.0012 & $* *$ & 0.0007 & $* *$ & 0.0000 & $* *$ & 0.0000 & & 0.0000 & \\
\hline$\alpha$ & 0.0320 & $* *$ & 0.0983 & $* *$ & 0.0486 & $* *$ & 0.0396 & $* *$ & 0.0346 & $* *$ \\
\hline$\beta$ & 0.5572 & $* *$ & 0.5741 & $* *$ & 0.9338 & $* *$ & 0.9440 & $* *$ & 0.9465 & $* *$ \\
\hline$\lambda$ & 0.0017 & $* *$ & 0.0017 & * & 0.0006 & $* *$ & 0.0005 & $*$ & 0.0006 & $* *$ \\
\hline$\psi_{\mathrm{EM}}$ & 0.0025 & $* *$ & 0.0008 & $* *$ & 0.0010 & $* *$ & 0.0014 & $* *$ & 0.0006 & $*$ \\
\hline$\psi_{\mathrm{BM}}$ & -0.0012 & $* *$ & & & & & & & 0.0008 & $* *$ \\
\hline$\psi_{\mathrm{EQ}}$ & -0.0005 & $* *$ & & & -0.0005 & $* *$ & & & & \\
\hline$\psi_{\mathrm{EY}}$ & -0.0000 & $* *$ & -0.0001 & $* *$ & & & & & & \\
\hline$E L A S T_{\mathrm{SR}}$ & 0.0156 & $* *$ & 0.0072 & * & 0.0017 & $* *$ & 0.0011 & $*$ & 0.0035 & $* *$ \\
\hline$E L A S T_{\mathrm{LR}}$ & 0.0353 & $* *$ & 0.0552 & * & 0.0259 & $* *$ & 0.0468 & $*$ & 0.0656 & $* *$ \\
\hline
\end{tabular}

VOLATILITY TRANSMISSION FROM THE FED FUNDS RATE

NOTE: Daily observations. Sample period: 1.3.1994 - 28.2.2006. An (two) asterisk(s) denotes statistical significance at $95 \%$ (99\%).

The focus of the exercise is on the coefficient $\lambda^{i}$. A positive value for the coefficient is consistent with the hypothesis that higher variance in the overnight market translates into higher variance for longer rates. For the FED Funds the coefficient is positive and significant in the variance equations for each maturity (Table 2). ${ }^{8}$ By looking at the 1-month market we

\footnotetext{
${ }^{8}$ As for the other coefficients, at longer maturities the levels of interest rates are less affected by calendar and maintenance period days both in the Euro area and USA. The ECT coefficient is significant only for the 1-
} 
can see that the pass-through is relatively small (0.0017). However, the magnitude of the estimated $\lambda^{i}$ is not a direct measure of the economic significance of the volatility transmission, since the volatility of the overnight market is usually much larger than that of longer rates. ${ }^{9}$

In the bottom panel of Table 2 we report two adjusted measures of this pass-through. The first is the average impact elasticity, $E L A S T_{S R}=\lambda^{i} \frac{\bar{\sigma}^{2, o n}}{\bar{\sigma}^{2, i}}$, i.e. the impact elasticity computed at the sample average of both volatilities. The second is the average equilibrium elasticity, computed as $E L A S T_{L R}=\frac{\lambda^{i}}{1-\beta^{i}} \frac{\bar{\sigma}^{2, o n}}{\bar{\sigma}^{2, i}}$. These elasticities give the percentage increase in the variance of rate $i$ due to a 1 percent increase in the variance of the overnight rate, when both variances are at average level. In particular, the equilibrium elasticity is more relevant to assess the impact of a permanent shift in the volatility of the FED Funds. According to these values, we found that the pass-through rate is around $1.5 \%$ for the 1 month at impact and much smaller at longer maturities. The adjustment in equilibrium is somehow stronger ranging between 3.5 and $6.6 \%$.

For the Euro area the evidence is similar to that of USA: there is a statistically significant transmission of volatility from the EONIA to longer-term rates, including the 10year benchmark rate (Table 3), though the volatility pass-through is quantitatively limited. The impact elasticity for the 1-month market is below $1.5 \%$, while that of the other maturities is even smaller. The equilibrium elasticity suggests again a stronger impact in the long-run: between 1.5 and 7.6\%. The similarity between the Euro area and the USA is confirmed by looking at the absolute transmission of the volatility: both the pass-through

month maturity; in addition it is much smaller than in the overnight model suggesting a significantly slower adjustment to official rate changes. There are no volatility transmission effects in the mean equation in any of the markets under analysis ( $k^{i}$ is not significantly different from zero), implying that the determination of the yields at longer maturities does not depend on the (conditional) volatility in the EONIA or the FED Funds rate.

${ }^{9}$ See figures 3 and 4 in the next Section for a comparison of market volatility levels across maturities. 
coefficient of equation (4) and the (average) conditional volatility in the overnight rates are of comparable magnitude. ${ }^{10}$

Table 3

VOLATILITY TRANSMISSION FROM THE EONIA RATE

\begin{tabular}{|c|c|c|c|c|c|c|c|c|c|c|}
\hline & 1-month & & 3-month & & 12-month & & 5-year & & 10-year & \\
\hline$\theta$ & 0.0086 & & 0.0017 & * & 0.0001 & & -0.0006 & & -0.0068 & $* *$ \\
\hline$\rho$ & -0.0185 & $* *$ & & & & & & & & \\
\hline$\varphi_{1}$ & 0.1896 & $* *$ & 0.5102 & $* *$ & 0.1230 & $* *$ & -0.0077 & $*$ & -0.0097 & \\
\hline$\eta_{0}$ & 0.2134 & $* *$ & 0.1765 & $* *$ & 0.1637 & $* *$ & 0.0639 & $* *$ & 0.0283 & $*$ \\
\hline$\tau$ & & & & & & & & & 4.0103 & $*$ \\
\hline$\omega_{\mathrm{EM}}$ & 0.0068 & * & & & & & & & & \\
\hline$\kappa$ & 0.0564 & & -0.0032 & & 0.0140 & & -0.0048 & & -0.0249 & \\
\hline$v$ & 0.0005 & $* *$ & 0.0003 & $* *$ & 0.0000 & $* *$ & 0.0000 & $* *$ & 0.0000 & $* *$ \\
\hline$\alpha$ & 0.0889 & $* *$ & 0.1396 & $* *$ & 0.0424 & $* *$ & & & 0.0271 & $* *$ \\
\hline$\beta$ & 0.5569 & $* *$ & 0.5227 & $* *$ & 0.9423 & $* *$ & 0.9476 & $* *$ & 0.9619 & $* *$ \\
\hline$\lambda$ & 0.0016 & $* *$ & 0.0011 & $* *$ & 0.0006 & $* *$ & 0.0007 & $*$ & 0.0005 & $*$ \\
\hline$\psi_{\mathrm{EM}}$ & -0.0013 & $* *$ & -0.0007 & $* *$ & 0.0003 & $* *$ & 0.0010 & $*$ & & \\
\hline$\psi_{\mathrm{EY}}$ & & & & & & & & & 0.0002 & $* *$ \\
\hline$\psi_{\mathrm{EMP}}$ & -0.0004 & $* *$ & -0.0008 & $* *$ & & & & & & \\
\hline$E L A S T_{\mathrm{SR}}$ & 0.0122 & $* *$ & 0.0015 & $* *$ & 0.0010 & $* *$ & 0.0034 & * & 0.0029 & $*$ \\
\hline$E L A S T_{\mathrm{LR}}$ & 0.0275 & $* *$ & 0.0269 & $* *$ & 0.0151 & $* *$ & 0.0644 & * & 0.0759 & $*$ \\
\hline
\end{tabular}

NOTE: Daily observations. Sample period: 1.1.1999 - 28.2.2006. An (two) asterisk(s) denotes statistical significance at 95\% (99\%).

In summary, the above evidence suggests that a limited part of the volatility in the short-end of the yield curve is transmitted to longer rates. As already mentioned, the volatility in the overnight rate is mostly related to the daily management of banks' liquidity while longer-term rates reflect broader expectations about future monetary policy and macroeconomic developments. Thus, at least theoretically, there shouldn't be any volatility spillover along the yield curve, especially at the 5- and 10-year horizon. ${ }^{11}$

\footnotetext{
${ }^{10}$ The conditional volatility in the overnight market is a generated regressor when used in the model for longer maturity rates and as such it may lead to an inefficient two-step estimation process if the (G)ARCH estimated in the first step is misspecified (Pagan and Ullah, 1987).

${ }^{11}$ Our findings are broadly consistent with the previous (limited) empirical literature. Relying on an EGARCH over the period between January 1999 and November 2003, Alonso and Blanco (2005) find a significant transmission of the EONIA volatility to the 1-month and 3-month rates, but not to the 12-month
} 


\section{A structural break test}

As mentioned in the Introduction, in the most recent period - at least from early 2000 - changes in the operational procedures, improved transparency, better communication and a trend over gradualism in monetary policy decisions has led to more efficient policy making and a reduced volatility in money markets. In this section we would like to assess whether this widespread improvement in the monetary policy framework has also had an impact on the "undesired" transmission of overnight interest rate volatility along the yield curve.

Figure 1

\section{LR TEST FOR A BREAK IN THE FED FUNDS VOLATILITY}

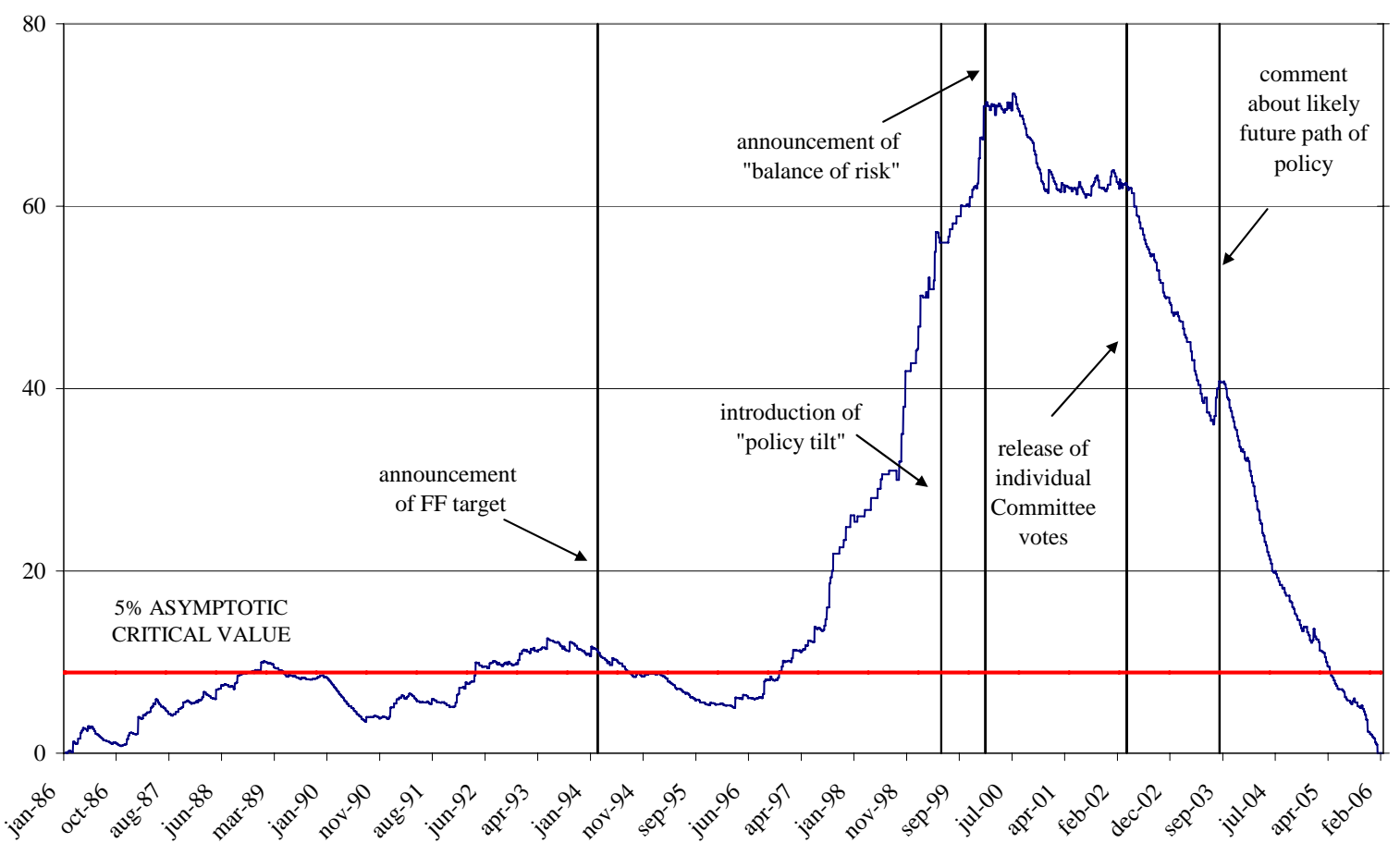

In order to evaluate whether a change in the estimates and patterns documented above has indeed occurred, we followed the testing procedure of Andrews (1993) and Andrews and

rate. For the USA, Abad and Novales (2004) and Lee (2006) hint to a limited volatility transmission which is often statistically significant at usual probability levels within the 12-month horizon. 
Ploberger (1994). In particular, the procedure is able to detect a structural break in the level of the volatility when the timing of the break is unknown. ${ }^{12}$

Figure 2

\section{LR TEST FOR A BREAK IN THE EONIA VOLATILITY}

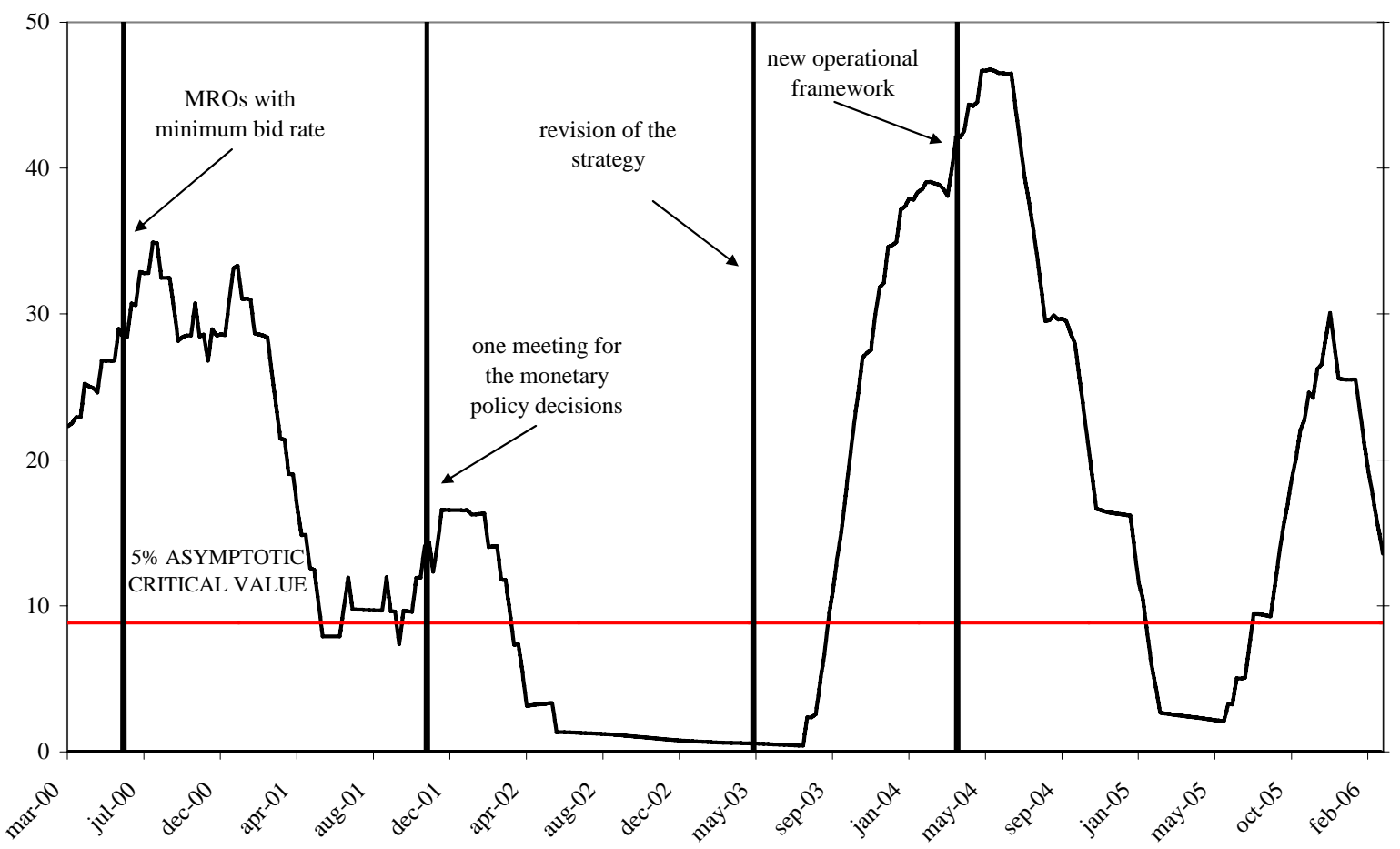

Figure 1 depicts the recursive value of the LR test for the FED Funds. Both average$L R$ and sup-LR statistics indicate a strong rejection of the null hypothesis of no structural change in the overnight volatility. In respect to the time of the structural break, the peak of the test is in July 2000. This date is not far from the introduction by the FED of an explicit

12 More precisely, we introduced a dummy $B(j)$ that equals 0 if $t \leq j$ and 1 otherwise in equation (4) and then we tested the null hypothesis that coefficient of $B(j)$ is 0 over all potential break dates $j, j \in\left[T_{1}, T_{2}\right]$, with $T_{1}=[0.15 T]$, and $T_{2}=[0.85 T]$ by means of standard $L R(j)$ statistics. Finally, we computed the average-LR and the sup- $L R$ test statistics. The asymptotic distributions of the tests are non standard and depend on the number of coefficients that are allowed to break and on the fraction of the sample that is examined (Andrews; 1993, Andrews and Ploberger; 1994). Moreover, the point at which the $\mathrm{LR}(j)$ statistic hits the maximum is an estimate of the break date. 
"balance of risks" warning to the economic outlook in the post-meeting statement (January 2000). Figure 1 shows vertical lines in correspondence with other important changes in the conduct and communication of the monetary policy, which in principle may have had an influence on the volatility of the overnight market. ${ }^{13}$ While multiple breaks are clearly possible, we do not pursue their identification here, and assume that a structural break in the volatility equation occurred in correspondence with the peak of the test in July 2000. The analogous exercise conducted on the Euro area overnight rate also reveals a likely structural break in the volatility equation (Figure 2). The maximum probability for a break is reached in May 2004, just after the implementation of the new operational framework adopted by the ECB in March 2004.

Figure 3

\section{Means of conditional variance in the USA}

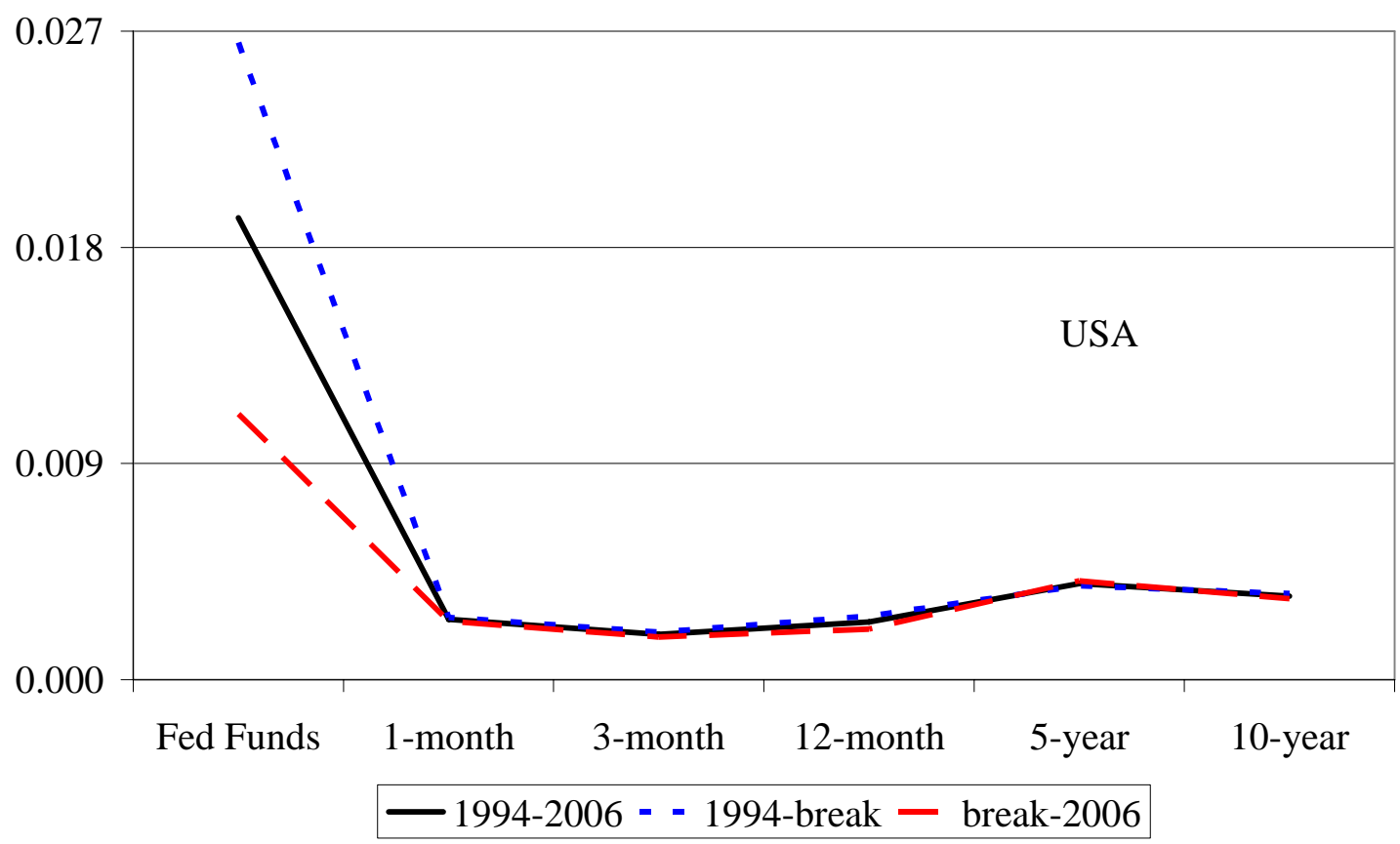

\footnotetext{
${ }^{13}$ See Swanson (2006) and Durré and Nardelli (2007) for a list of all relevant changes in the monetary policy conduct of the FED and ECB. Eijffinger and Geraats (2006) propose an index which measures the improvement in transparency over time due to adjustments in the communication strategy and the operational framework of 9 major Central banks.
} 
Figures 3 and 4 depict the pattern of volatility in each market for both economies under analysis. It is evident that the volatility has decreased in the second half of the sample (after the break), especially in the overnight markets. Also note that, consistently with the findings of Ayuso et al. (1997) for some European countries and Alonso and Blanco (2005) for the Euro Area, the U-shaped pattern of the volatility across maturities up to 12 months is maintained, while the curve exhibits an overall snake-shaped behaviour due to the reduction of volatility at the 10-year horizon (Piazzesi, 2005).

Figure 4

\section{Means of conditional variance in the Euro Area}

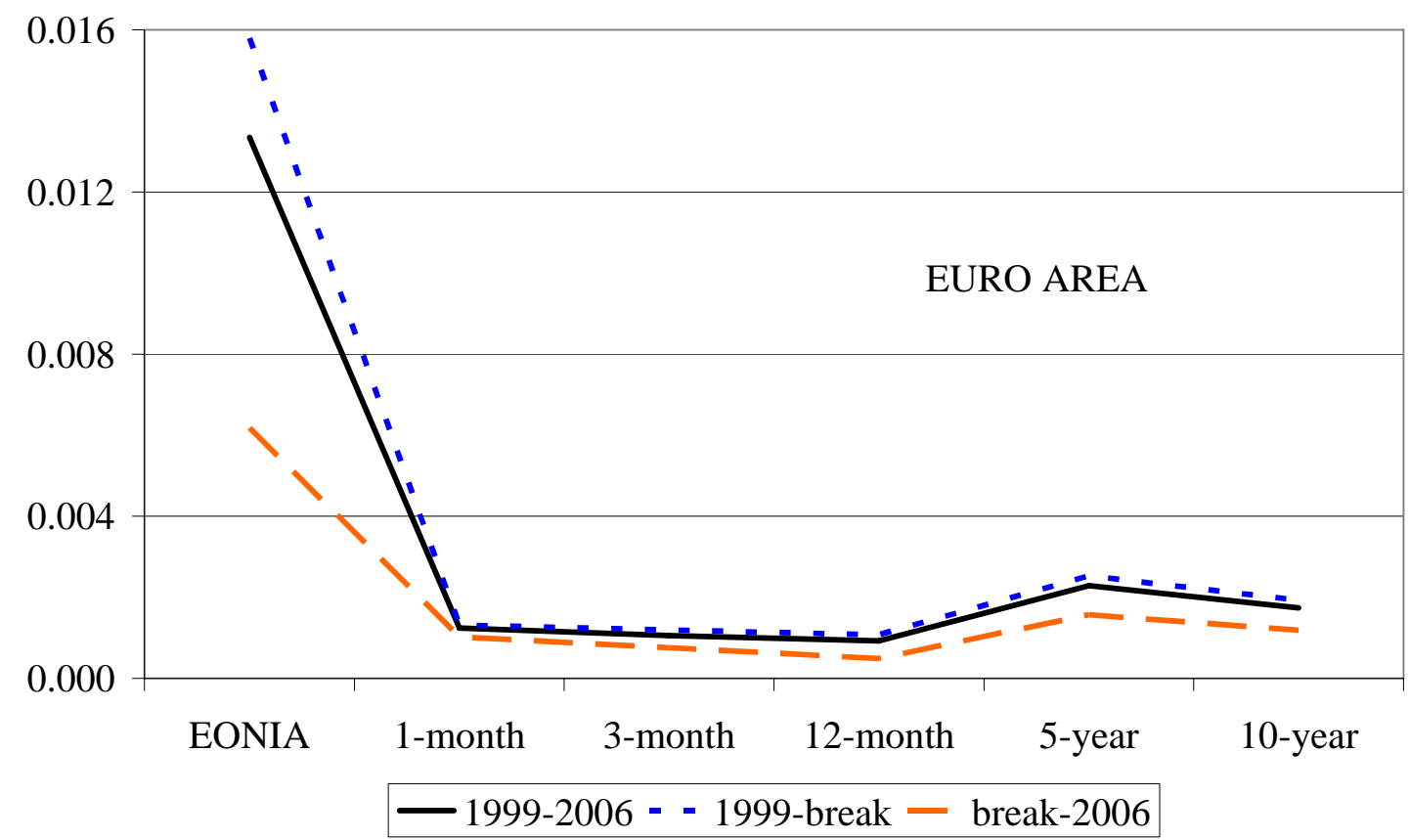

Needless to say, the aspect we would like to assess is whether the volatility transmission from the money market has changed after the break in the overnight volatility level. To check for the change, we introduce a $d u B R E A K$ step-dummy in our regressions and consider the conditional overnight volatility derived from the model assuming the structural break. $^{14}$

\footnotetext{
14 The estimates of equations (1)-(2) for the overnight markets obtained assuming one break (in July 2000 for the US and in May 2004 for the Euro area) are reported in Table A3 in the Appendix.
} 
Specifically, for all rates we leave equation (3) unchanged and we model volatility as follows:

(5) $\sigma^{2, i}{ }_{t}=v^{i}+\alpha \varepsilon^{2, i}{ }_{t-1}+\beta^{i} \sigma_{t-1}^{2, i}+\lambda_{0}^{i} \sigma_{t}^{2, o n}+\lambda_{1}^{i} d u B R E A K \sigma_{t}^{2, o n}+\delta d u B R E A K+\psi^{i} D X$.

A significant value of $\lambda_{1}^{i}$ would suggest a change in the volatility spill-over across markets. In particular, a positive (negative) value would hint to an increased (reduced) passthrough, while the non-significance of the estimate would point to an unchanged framework.

Table 4

STRUCTURAL CHANGES IN VOLATILITY TRANSMISSION

\begin{tabular}{|c|c|c|c|c|c|c|c|c|c|c|}
\hline \multicolumn{11}{|c|}{ Federal Funds } \\
\hline & 1-month & & 3-month & & 12-month & & 5 -year & & 10-year & \\
\hline$v$ & 0.0007 & $* *$ & 0.0001 & $* *$ & $0.0001^{* *}$ & $* *$ & 0.0001 & $* *$ & 0.0000 & $*$ \\
\hline$\alpha$ & 0.2420 & $* *$ & 0.0551 & $* *$ & 0.0486 ** & $* *$ & 0.0164 & $* *$ & 0.0411 & ** \\
\hline$\beta$ & 0.5215 & $* *$ & 0.7740 & $* *$ & 0.6740 ** & $* *$ & 0.8307 & $* *$ & 0.9347 & ** \\
\hline$\lambda_{0}$ & 0.0034 & $* *$ & 0.0019 & $* *$ & 0.0011 ** & $* *$ & 0.0018 & * & 0.0009 & ** \\
\hline$\lambda_{1}$ & -0.0033 & $* *$ & -0.0014 & $* *$ & $-0.0005^{* *}$ & $* *$ & -0.0012 & * & -0.0005 & $*$ \\
\hline$\delta$ & -0.0007 & $* *$ & -0.0001 & $*$ & $-0.0001 *$ & & 0.0000 & & 0.0000 & \\
\hline \multicolumn{11}{|c|}{ EONIA } \\
\hline & 1-month & & 3-month & & 12-month & & 5 -year & & 10-year & \\
\hline$v$ & 0.0005 & $* *$ & 0.0003 & $* *$ & 0.0000 & & 0.0001 & ** & 0.0000 & \\
\hline$\alpha$ & 0.0272 & $* *$ & 0.0143 & $*$ & 0.0453 ** & $* *$ & 0.0491 & ** & 0.0178 & $* *$ \\
\hline$\beta$ & 0.4394 & $* *$ & 0.4969 & $* *$ & 0.9290 ** & $* *$ & 0.9402 & ** & 0.9677 & $* *$ \\
\hline$\lambda_{0}$ & 0.0018 & $* *$ & 0.0030 & $* *$ & $0.0008^{* *}$ & $* *$ & 0.0011 & * & 0.0016 & $*$ \\
\hline$\lambda_{1}$ & -0.0015 & $* *$ & -0.0032 & $* *$ & $-0.0005 *$ & * & -0.0018 & * & -0.0007 & $*$ \\
\hline$\delta$ & -0.0004 & $* *$ & -0.0001 & $* *$ & 0.0000 & & 0.0000 & & 0.0000 & \\
\hline
\end{tabular}

Daily observations. Sample period: 1.03.1994 - 28.2.2006 for USA and 1.1.1999 28.2.2006 for Euro area. An (two) asterisk(s) denotes statistical significance at 95\% (99\%).

Tables 4 shows the estimated results for both economies and for each market. The remarkable result is that the volatility transmission from the overnight market has strongly diminished in the second half of the sample in all markets for both currencies. The coefficient of the multiplicative dummy is always negative and significantly different from zero in each specification, while the coefficient $\lambda_{0}^{i}$ is always significant and usually larger than the corresponding estimate over the broad sample (see Table 3), suggesting that indeed in the first part of the sample the transmission was stronger. In addition, the Wald test never 
rejects the null hypothesis that the sum of the transmission coefficients is zero thus suggesting that the volatility transmission has completely vanished in the most recent period.

Of course the underlying causes of the improved functioning of the money market cannot be determined with certainty since many factors may have concurred with the final outcome. Although the improvement is likely to have been gradual rather than directly linked to a single episode, our results are fully consistent with the hypothesis that an improved general framework of monetary policy decision-making has contributed to the vanishing of an undesired volatility spillover across maturities. In addition, Table 4 shows that for some markets the dummy variable for a break in the level of volatility is nonsignificantly different from zero at the usual confidence levels, thus suggesting that the vanishing of the volatility pass-through is independent of a possible reduction of volatility in each market. This in turn suggests that it might be a phenomenon attributable to a different source than the "good luck" hypothesis or the supposed improved ability of the economic system as a whole to withstand shocks. What we suggest is that indeed the more open, gradual and transparent behaviour on the part of Central banks has let financial agents operate in an increasingly efficient way.

\section{Conclusion}

The efficient functioning of the overnight market plays a key role in the financial structure and in the monetary policy conduct of most world economies. On the one hand, overnight rates are the anchor for the term structure of interest rates, but on the other, operating procedures of central banks are designed to affect the supply and demand of liquidity reserves among credit institutions. Thus, volatility transmission along the yield curve may weaken the signalling power of the monetary policy stance. Also the transmission mechanism of monetary policy impulses may be concerned by a large volatility spillover from overnight to longer-term rate.

In order to maintain a low level of volatility, Central banks have devised various ways in which they directly and indirectly affect the liquidity conditions in the overnight market. In the last two decades, we have witnessed an overall increase in the transparency of Central banking, improved communication strategies and a gradual approach in the decision making 
process. Additionally the operational framework has undergone a series of improvements in order to maintain a "neutral" liquidity policy, i.e. the monetary policy stance has to be determined only by the decisions taken by the Central bank concerning the official rates. Since the monetary authority operational rules have a clear influence on the functioning of the overnight market, any change in the framework may affect the dynamics of the short-end of the yield curve. Thus, the behavioural features of interbank markets need not be taken as given by policy-makers, but can be expected to respond readily and predictably to changes in institutional arrangements (Prati et al.; 2003). This in turn implies that the analysis of possible structural breaks in the transmission of volatility along the yield curve might be readily used as a good indicator of the consequences of the quoted measures in monetary policy management.

By relying on a common empirical framework for the USA and Euro area we showed that the conditional overnight volatility is a significant explanatory variable in the volatility equation of a GARCH model for the 1-month, 3-month, 12-month, 5-year and 10-year rates over the period ending in February 2006. This might have reflected an inadequate understanding of Central banks decision-making process or insufficient communication to the financial markets and the public at large. In addition, an imperfect design of the operational framework could have let financial market's expectations about future policy decisions interfere with the standard overnight dynamics. However, splitting the sample in order to isolate the most recent period of improved policy-making, we discovered that the volatility pass-through has entirely disappeared in both economies. In particular, through a structural break test procedure with unknown break-date we found evidence that the relationship broke down soon after specific interventions in the policy conduct of the FED and ECB. Although our exercise is not a direct test of the effectiveness of the changes in both monetary policy strategy and operational framework, our results are consistent with significant positive effects of the move towards a more open and gradual approach in the changes in the official interest rates and the improved operational setting devised by Central banks.

In addition, our results are in line with the current findings of the empirical literature on monetary policy conduct. In particular, the improvement in private sector forecasts of short-term interest rates (Lange et al.; 2003, Swanson; 2006, Bauer et al.; 2006), the reduced 
macroeconomic and financial volatility (Cecchetti; 2006, CGFS; 2006) and the increased predictability of the Central bank decisions (Bernoth and von Hagen; 2004, Wilhelmsen and Zaghini; 2005, Ehrmann and Fratzscher; 2006) are all aspect that may be directly or indirectly linked to the new era of openness, transparency and gradualism. 


\section{Appendix}

\section{Table A1}

Data definition

\begin{tabular}{|c|c|c|c|c|c|c|c|}
\hline & Policy rate & Overnight & 1-month & 3-month & 12-month & 5-year & 10-year \\
\hline USA & $\begin{array}{l}\text { Federal } \\
\text { funds target } \\
\text { rate }\end{array}$ & $\begin{array}{l}\text { Federal } \\
\text { funds } \\
\text { effective } \\
\text { rate }\end{array}$ & $\begin{array}{l}\text { LIBOR US } \\
\text { dollar 1- } \\
\text { month }\end{array}$ & $\begin{array}{l}\text { LIBOR US } \\
\text { dollar 3- } \\
\text { month }\end{array}$ & $\begin{array}{l}\text { LIBOR US } \\
\text { dollar 12- } \\
\text { month }\end{array}$ & $\begin{array}{l}\text { yield on the } \\
\text { 5-year } \\
\text { Treasury } \\
\text { benchmark }\end{array}$ & $\begin{array}{l}\text { yield on the } \\
10 \text {-year } \\
\text { Treasury } \\
\text { benchmark }\end{array}$ \\
\hline Euro area & $\begin{array}{l}\text { rate on the } \\
\text { main } \\
\text { refinancing } \\
\text { operations }^{1)}\end{array}$ & EONIA & $\begin{array}{l}\text { EURIBOR } \\
\text { 1-month }\end{array}$ & $\begin{array}{l}\text { EURIBOR } \\
\text { 3-month }\end{array}$ & $\begin{array}{l}\text { EURIBOR } \\
\text { 12-month }\end{array}$ & $\begin{array}{l}\text { yield on the } \\
\text { 5-year } \\
\text { German } \\
\text { government } \\
\text { benchmark }\end{array}$ & $\begin{array}{l}\text { yield on the } \\
10 \text {-year } \\
\text { German } \\
\text { government } \\
\text { benchmark }\end{array}$ \\
\hline
\end{tabular}

1) For MROs held through variable rate tenders we took the minimum bid rate (the lower limit at which counterparties may submit bids.

Source: Datastream

Table A2

\section{Dummy specification}

\begin{tabular}{ll}
\hline EM & End of month \\
BM & Beginning of month \\
EQ & End of quarter \\
EY & End of year \\
EMP & End of maintenance period \\
EEMP & One day before the end of the maintenance period \\
EEEMP & Two days before the end of the maintenance period \\
$\mathbf{9 / 1 1 / 2 0 0 1}$ & Last three days of the maintenance period including $11^{\text {th }}$ Sept 2001 and first day \\
\hline
\end{tabular}


Table A3

Structural break in the overnight market

\begin{tabular}{|c|c|c|c|c|c|}
\hline \multicolumn{6}{|c|}{ Fed Funds } \\
\hline$\theta$ & -0.0024 & * & $v$ & 0.0070 & $* *$ \\
\hline$\rho$ & -0.7853 & $* *$ & $\alpha$ & 0.3755 & $* *$ \\
\hline$\varphi_{1}$ & 0.0874 & $* *$ & $\beta$ & 0.0475 & $* *$ \\
\hline$\varphi_{2}$ & 0.0731 & $* *$ & $\gamma$ & 0.0255 & \\
\hline$\varphi_{3}$ & 0.0923 & $* *$ & $\psi_{\mathrm{EM}}$ & 0.0030 & $*$ \\
\hline$\eta_{0}$ & 0.5868 & $* *$ & $\psi_{\mathrm{EQ}}$ & 0.2522 & $* *$ \\
\hline$\omega_{\mathrm{EM}}$ & 0.0714 & $* *$ & $\psi_{\text {EEEMP }}$ & 0.0005 & $*$ \\
\hline$\omega_{\mathrm{BM}}$ & 0.0303 & $* *$ & $\psi_{\text {EEMP }}$ & 0.0029 & $* *$ \\
\hline$\omega_{\mathrm{EQ}}$ & 0.3503 & $* *$ & $\psi_{\text {EMP }}$ & 0.0010 & $* *$ \\
\hline$\omega_{\mathrm{EY}}$ & -0.6030 & $* *$ & duBREAK & -0.0061 & $* *$ \\
\hline$\omega_{\text {EEEMP }}$ & 0.0202 & $* *$ & & & \\
\hline$\omega_{\mathrm{EMP}}$ & 0.0150 & $*$ & & & \\
\hline$\omega_{9 / 11 / 2001}$ & -1.0739 & $* *$ & & & \\
\hline \multicolumn{6}{|c|}{ EONIA } \\
\hline$\theta$ & 0.0043 & & $v$ & 0.0029 & $* *$ \\
\hline$\rho$ & -0.2297 & $* *$ & $\alpha$ & 0.3885 & $* *$ \\
\hline$\varphi_{1}$ & -0.0536 & $*$ & $\beta$ & 0.2676 & $* *$ \\
\hline$\eta_{0}$ & 0.4007 & $* *$ & $\psi_{\mathrm{EM}}$ & 0.0012 & $* *$ \\
\hline$\omega_{\mathrm{EM}}$ & 0.0360 & $* *$ & $\psi_{\mathrm{BM}}$ & -0.0034 & $* *$ \\
\hline \multirow[t]{4}{*}{$\omega_{\mathrm{EQ}}$} & 0.0731 & $* *$ & $\psi_{\text {EEEMP }}$ & 0.0049 & $* *$ \\
\hline & & & $\psi_{\text {EEMP }}$ & 0.0181 & $* *$ \\
\hline & & & $\psi_{\text {EEMP }}$ & 0.0352 & $* *$ \\
\hline & & & duBREAK & -0.0028 & $* *$ \\
\hline
\end{tabular}

NOTE: Daily observations. Sample period: 1.3.1994 - 28.2.2006 for the USA and 1.1.1999 - 28.2.2006 for the Euro Area. An (two) asterisk(s) denotes statistical significance at 95\% (99\%). 


\section{References}

Abad, P. and A. Novales (2004), "Volatility Transmission across term structure of swap markets: international evidence”, Applied Financial Economics, Vol.14, pp.1045.1058.

Alonso, F. and R. Blanco (2005), "Is the volatility of the EONIA transmitted to longer-term euro money market interest rates?”, Documentos de Trabajo No.0541, Banco de Espagna.

Andrews, D.W.K. (1993), “Test for Parameter Instability and Structural Change with Unknown Change Point”, Econometrica, Vol.61, No.4, pp.821-856.

Andrews, D.W.K. and W. Ploberger (1994), "Optimal Tests when a nuisance Parameter is Present Only Under the Alternative”, Econometrica,Vol.62, No.6, pp.1383-1414.

Andersen, T. and T. Bollerslev (1997), "Intraday periodicity and volatility persistence in financial markets”, Journal of Empirical Finance, Vol.4, pp.115-158.

Andersen, T. and T. Bollerslev (1998), “Answering the skeptics: yes, standard volatility models do provide accurate forecasts”, International Economic Review, Vol.39, pp. 885-905.

Angeloni, I., G. Coenen and F. Smets (2003), "Persistence, the Transmission Mechanism and Robust Monetary Policy”, Scottish Journal of Political Economy, Vol. 50, No.5, pp.527-549.

Ayuso, J., A.G. Haldane and F. Restoy (1997), "Volatility Transmission along the Money Market Yield Curve”, Weltwirtschafltiches Archiv, Vol.133, pp.56-75.

Bali, T.G. and L. Wu (2006), "A Comprehensive Analysis of the Short-term Interest-rate Dynamics”, Journal of Banking and Finance, Vol.30, pp.1269-1290.

Bartolini, L., G. Bertola and A. Prati (2002), "Day-To-Day Monetary Policy and the Volatility of the Federal Funds Interest Rate”, Journal of Money, Credit, and Banking, Vol.34, No.1, pp.137-159.

Bartolini, L. and A. Prati (2006), "Cross-country differences in monetary Policy Execution and Money Market Rates’ Volatility”, European Economic Review, Vol.50, pp.349-376.

Bauer, A., R. Eisenbeis, D. Waggoner and T. Zha (2006), “Transparency, Expectations and Forecasts”, ECB Working Paper, No.637.

Bernake, B. (2004), “Gradualism”, Remarks at an economics luncheon by the Federal Reserve Bank of San Francisco and the University of Washington, Seattle, Washington.

Board of Governors of the Federal Reserve System (2005), The Federal Reserve System: Purposes \& Functions, Washington, D.C.

Bomfim, A.N. (2003), "Pre-announcement Effects, News Effects, and Volatility: Monetary Policy and the Stock Market”, Journal of Banking and Finance, Vol.27, pp.133-151.

Bollerslev, T. (1986), “Generalized Autoregressive Conditional Heteroskedasticity”, Journal of Econometrics, Vol.31, pp. 307-327.

Bernoth, K. and J. von Hagen (2004), “The Euribor Futures Market: Efficiency and the Impact of ECB Policy Announcements”, International Finance, Vol.7, No.1, pp-1-24.

Brainard, W. (1967), Uncertainty and the Effectiveness of Policy”, American Economic Review, Vol.57, pp.411-425. 
Cecchetti, S.G., A. Flores-Lagunes and S. Krause (2006), "Has Monetary Policy Become more Efficient? A Cross-country Analysis”, Economic Journal, Vol.116, pp.408-433.

Clews, R. (2005), “Implementing Monetary Policy: Reforms of the Bank of England's Operations in the Money Market, Bank of England Quarterly Bulletin.

Committee on the Global Financial System (2006), "The Recent Decline in Financial Market Volatility: Main Causes and Consequences”, CGFS Publication No.27, Bank for International Settlements, Basel.

Demiralp, S. and O. Jordà (2004), “The Response of Term Rates to FED Announcements”, Journal of Money, Credit, and Banking, Vol.36, No.3, pp.387-405.

Demiralp, S., Preslopsky, B. and Whitesell, W. (2006), “Overnight Interbank Loan Markets”, Journal of Economics \& Business, Vol.58, No.1, pp.67-83.

Durré, A. and S. Nardelli (2007), "Volatility in the euro area money market: Effects from the monetary policy operational framework", mimeo, ECB.

Ehrmann, M. and M. Fratzscher (2006), “Communication by Central Bank Committee Members: Different Strategies, Same Effectiveness?”, Journal of Money, Credit, and Banking, forthcoming.

Eijffinger, S.C.W. and P.M. Geraats (2006), "How Transparent are Central Banks”, European Journal of Political Economy, Vol.22, No.1, pp.1-21.

Engle, R.F. (1983), "Estimates of the Variance of US Inflation Based upon the Arch Model”, Journal of Money, Credit, and Banking, Vol.15, No.3, pp.286-301.

European Central Bank (2005), The implementation of monetary policy in the euro area, Frankfurt am Main.

Furfine, C.H. (2003), "Standing Facilities and Internbank Borrowing: Evidence from the Federal Reserve New Discount Window”, International Finance, Vol.6, No.3, pp.329-347.

Glosten, R.L., Jagannathan, R. and Runkle, D.E. (1993), “On the relation between the expected value and the volatility of the nominal excess return on stocks", Journal of Finance, Vol.48, No.5, pp.1779-1801.

Hartmann, P., M. Manna and A. Manzanares (2001), "The microstructure of the euro money market”, Journal of International Money and Finance, Vol.20 No.6, pp.895-948.

Hilton, S. (2005), “Trends in Federal Funds Rate Volatility”, Federal Reserve Bank of New York, Current Issues in Economics and Finance, Vol.11, No.7, pp.1-8.

Issing, O. (2005), "Communication, Transparency, Accountability: Monetary policy in the Twenty-First Century”, FED St. Louis Review, Vol.87, No.2, pp.65-83.

Lange, J., B. Sack and W. Whitesell (2003), “Anticipation of Monetary Policy in Financial Markets”, Journal of Money, Credit, and Banking, Vol.35, No.6, pp.889-909.

Lee, J. (2006), “The Impact of Federal Funds Target Changes on Interest Rate Volatility”, International Review of Economics and Finance, Vol.15, pp.241-259.

Moschitz, J. (2004), "The determinants of the overnight interest rate in the Euro area”, ECB Working Paper No.393. 
Nautz, D. and C.J. Offermanns (2007); “The dynamic relationship between the Euro overnight rate, the ECB's policy rate and the term spread”, International Journal of Finance and Economics, forthcoming.

Orphanides, A. (2003), "Monetary Policy Evaluation with Noisy Information”, Journal of Monetary Economics, Vol.50, pp.605-631.

Pagan, A. and A. Ullah (1988), “The Econometric Analysis of Models with Risk Terms", Journal of Applied Econometrics, Vol.3, pp.87-105.

Piazzesi, M. (2005), "Bond Yields and the Federal Reserve”, Journal of Political Economy, Vol.113, No.2, pp.311-344.

Perez-Quiros, G. and H. Rodriguez Mendizabal (2006), “The Daily Market for Funds in Europe: What has Changed with the EMU?”, Journal of Money, Credit, and Banking, Vol.38, No.1, pp.91-110.

Prati, A., L. Bartolini and G. Bertola (2003), “The Overnight Interbank Market: Evidence from the G-7 and Euro Zone”, Journal of Banking and Finance, Vol.27, pp.2045-2083.

Rudebush, G. (2001), “Is the FED Too Timid? Monetary Policy in an Uncertain World”, Review of Economics and Statistics, Vol.83, pp.203-217.

Söderström, U. (2002), “Monetary Policy with Uncertain Parameters”, Scandinavian Journal of Economics, Vol.104, pp.125-145.

Stock, J.H. and M.W. Watson (2002), “Macroeconomic Forecasting Using Diffusion Indexes”, Journal of Business \& Economic Statistics, Vol.20, No.2, pp.147-162.

Swanson, E.T. (2006), "Have Increases in Federal Reserve Transparency Improved Private Sector Interest Rate Forecast?”, Journal of Money, Credit and Banking, Vol.38, No.3, pp.791-820.

Wilhelmsen, B.R. and A. Zaghini (2005), "Monetary Policy Predictability in the Euro Area: an International Comparison”, ECB Working Paper, No.504.

Woodford, M. (2003), “Optimal Monetary Policy Inertia”, Review of Economic Studies, Vol.70, pp.861-886.

Woodford, M. (2005), "Central Bank Communication and Policy Effectiveness”, NBER Working Paper No.11898. 


\section{CFS Working Paper Series:}

No.

2007/14 Annamaria Lusardi

Olivia S. Mitchell

2007/14 Jean Boivin

Marc P. Giannoni

Ilian Mihov

2007/13 Virgiliu Midrigan

2007/12 Michael Woodford

2007/11 Lars E. O. Svensson Noah Williams

2007/10 Alessandro Calza Tommaso Monacelli Livio Stracca

2007/09 Mark Gertler Antonella Trigari

2007/08 Olivier Blanchard Jordi Galí

2007/07 Kai Christoffel Keith Kuester Tobias Linzert

2007/06 Gauti B. Eggertsson Banjamin Pugsley
Title

Financial Literacy and Retirement Preparedness:

Evidence and Implications for Financial Education Programs

Sticky Prices and Monetary Policy: Evidence from Disaggregated U.S. Data

Menu Costs, Multi-Product Firms, and Aggregate Fluctuations

Robustly Optimal Monetary Policy with NearRational Expectations

Bayesian and Adaptive Optimal Policy under Model Uncertainty

Mortgage Markets, Collateral Constraints, and Monetary Policy: Do Institutional Factors Matter?

Unemployment Fluctuations with Staggered Nash Wage Bargaining

A New Keynesian Model with Unemployment

Identifying the Role of Labor Markets for Monetary Policy in an Estimated DSGE Model

The Mistake of 1937: A General Equilibrium Analysis

Copies of working papers can be downloaded at http://www.ifk-cfs.de 